\title{
Potencialidade de processamento industrial de cultivares de batatas
}

\author{
Industrial processing potential of potato cultivars \\ Émerson Loli Garcia ${ }^{\mathrm{I}}$ Ezequiel Lopes do Carmo ${ }^{\mathrm{II}}$ \\ Joaquim Gonçalves de Pádua ${ }^{\mathrm{III}}$ Magali Leonel ${ }^{{ }^{*}}$
}

\section{RESUMO}

A industrialização da batata tem sido limitada no Brasil, devido à falta de matéria-prima adequada, sendo a demanda suprida pelas importações de produtos processados. Oito cultivares de batata, adaptadas às condições da região serrana de Minas Gerais, safra 2011, foram avaliadas quanto a sua composição centesimal, cor e conteúdo de amilose. Os resultados obtidos mostraram que as cultivares 'Marcy' $e$ 'Colorado' apresentam características importantes para o cozimento. As cultivares 'Marlen' e 'Pirassu' apresentam atributos requeridos para o processamento na forma de chips elou palha e a cultivar 'BRS Ana' para a forma de palitos pré-fritos.

Palavras-chave: batata, Solanum tuberosum, cor, amido, fibras.

\section{ABSTRACT}

The industrialization of potato in Brazil has been limited because of the low availability of tubers with adequate quality, being supplied by imports of processed products demand. Eight cultivars of potato, adapted to the mountainous conditions of Minas Gerais state, harvest of 2011, were evaluated for their centesimal composition, color and amylose content. The results demonstrated that 'Marcy' and 'Colorado' cultivars showed important characteristic for cooking. The 'Marlen' and 'Pirassu' cultivars showed required attributes for processing in the form of chips or straw and the cultivar 'BRS Ana'for pre-fried sticks.

Key words: potato, Solanum tuberosum, color, starch, fiber.

\section{INTRODUÇÃO}

A batata (Solanum tuberosum L.) é a olerácea brasileira de maior relevância econômica para o país (FILGUEIRA, 2005). Em 2013, a área plantada foi de 127 mil hectares com uma produção agrícola de 3,5 milhões de toneladas, representando um montante superior a R\$ 1,4 bilhão para a economia do país (IBGE, 2013).

As cultivares de batata existentes no Brasil não estão totalmente adaptadas às condições sazonais de um país tropical, podendo, reduzir a produtividade e a qualidade da batata, quando comparada à batata produzida em países de clima temperado (PINTO, 2001). Desse modo, tornase essencial a identificação dos parâmetros de qualidade dos tubérculos, pois estes irão predizer a qualidade do produto final (ANDREU et al., 2007).

O Brasil é auto-suficiente na produção para o mercado do tubérculo in natura e processamento doméstico, porém, depende de importação de grande parte da batata processada, principalmente na forma de batata pré-frita congelada e batata palito, assim como de todo o amido procedente de batata que o país consome (PÁDUA et al., 2007).

Um dos fatores que contribui para expansão do consumo de batata no mundo é a facilidade de seu preparo (HAASE, 2008), podendo a batata ser considerada um alimento minimamente processado, pois alia a conveniência e qualidade de produto fresco (CABEZAS-SERRANO et al., 2009) com a disponibilidade durante o ano todo. No Brasil, a batata processada na forma de chips e palitos préfritos apresentou o segundo maior crescimento

\footnotetext{
'Universidade Estadual Paulista "Júlio de Mesquita Filho" (CERAT/UNESP), Rua José Barbosa de Barros, 1780, 18610-307, Botucatu, SP, Brasil. E-mail: mleonel@cerat.unesp.br. *Autor para correspondência.

IIInstituto Federal do Mato Grosso (IFMT), Campo Novo do Parecis, MG, Brasil.

IIINúcleo Tecnológico de Batata e Morango, Empresa de Pesquisa Agropecuária de Minas Gerais (EPAMIG), Pouso Alegre, MG, Brasil.
} 
no setor industrial de alimentos no ano de 2010 (SILVEIRA et al., 2011).

Um importante fator a ser considerado no processamento de batata é o desenvolvimento de cultivares que atendam às exigências de qualidade de cada tipo de processamento, sendo os principais parâmetros divididos em: características agronômicas (produtividade, resistência às pragas e doenças, adaptação climática, etc.) e composição química (teor de matéria seca, teor de açúcares e características da fração amilácea) (LEONEL et al., 2011).

Oconteúdo de matéria seca afeta orendimento industrial e a textura da batata processada (ROMMENS et al., 2010), já os açúcares redutores podem reagir com aminoácidos, causando escurecimento e conferindo sabor amargo à batata processada (SANNY et al. (2012).

O amido é o principal carboidrato de reserva dos tubérculos, sendo formado pelos polímeros amilose e amilopectina, e a relação destes interfere nas propriedades funcionais e em sua aplicação industrial. Para o processamento na forma de chips, teor elevado de amilose é desejável por conferir maior crocância à batata (TAGGART, 2004).

Este trabalho objetivou avaliar as propriedades físicas, químicas e físico-químicas de diferentes cultivares de batata, visando suprir o setor de informações importantes para a aplicabilidade industrial de diferentes cultivares.

\section{MATERIAL E MÉTODOS}

Foram utilizados tubérculos de batata das cultivares: 'Snowden', 'Harley Beckhell', 'Marlen', 'Colorado', 'BRS Ana', 'Pirassu', 'Beacon Chipper' e 'Marcy', cultivados no município de Pouso Alegre, região serrana ao sul de Minas Gerais, colhidas com aproximadamente cinco meses após o plantio, safra 2011.

Após a colheita, os tubérculos foram encaminhados ao Laboratório de Análises do Centro de Raízes e Amidos Tropicais da Unesp/Botucatu - CERAT, onde os tubérculos foram higienizados em água potável para posterior caracterização da composição centesimal, cor e teor de amilose. Para as análises de cor, fatias transversais dos tubérculos foram obtidas e submetidas ao colorímetro Minolta (CR-400), utilizando-se da escala CIELAB: *L (luminosidade), variando do preto $(0)$ ao branco (100); $\mathrm{a}^{*}$ indica variação da cor, verde (-60) ao vermelho (+60); $b^{*}$ indica variação de cor do azul (-60) ao amarelo $(+60)$; o ângulo de cor $\left({ }^{\circ} \mathrm{h}=\tan ^{-1}\left(\mathrm{~b}^{*} / \mathrm{a}^{*}\right)\right.$ indica a tonalidade $\left(0^{\circ}\right.$ vermelho, $90^{\circ}$ amarelo, $180^{\circ}$ verde, $270^{\circ}$ azul) e o chroma $\left(C^{*}=\sqrt{ }\left(a^{*}\right)^{2}+\left(b^{*}\right)^{2}\right)$ a intensidade da cor.

Após a análise de cor, os tubérculos foram desidratados em estufa (Marconi, modelo MA-037) com circulação de ar forçada a $55^{\circ} \mathrm{C}$, sendo, posteriormente, moídos em moinho de facas (Marconi, modelo MA340). A seguir, o material foi acondicionado em recipientes plásticos de polietileno com tampas para posterior caracterização da composição centesimal e teor de amilose aparente. Todas as análises foram realizadas em triplicatas e os resultados expressos em base úmida.

A umidade foi determinada conforme método proposto por AOAC (2007). As amostras foram colocadas em estufa a $105^{\circ} \mathrm{C}$ por 8 horas até obtenção de massa constante, sendo, posteriormente resfriadas em dessecador e pesadas. $\mathrm{O}$ conteúdo de matéria seca foi obtido por diferença. $\mathrm{O}$ teor de cinzas foi determinado submetendo as amostras à combustão em mufla por duas horas a $550^{\circ} \mathrm{C}$ e o teor de proteína pelo método de Kjeldahl, conforme metodologia AOAC (2007), com o fator 6,25 utilizado para a conversão de nitrogênio em proteína.

Para determinação do teor de lipídios, foram utilizados $3 \mathrm{~g}$ de amostra e realizada a extração em Soxleth, utilizando éter de petróleo para arraste (AOAC, 2007). $\mathrm{O}$ teor de fibra alimentar foi obtido por hidrólise ácida, seguida por hidrólise alcalina, quando foram utilizados $3 \mathrm{~g}$ de cada amostra processada em bloco digestor de fibras (AOAC, 2007).

O conteúdo de açúcares totais foi determinado pelo método de Somogy, adaptado por NELSON (1944). Pesaram-se 500mg de amostra em erlenmeyer, acrescentou-se $60 \mathrm{~mL}$ de etanol a $50 \%$ e, em seguida, a amostra foi colocada em banho com aquecimento a $65^{\circ} \mathrm{C}$ por 60 minutos. Após, foi acrescentado $1 \mathrm{~mL}$ de $\mathrm{HCl}$ P.A. e as amostras retornaram ao banho por mais 60 minutos. Em seguida, foram resfriadas, neutralizadas e diluídas.

O teor de amido foi obtido pelo método de hidrólise enzimática. Foram transferidos $200 \mathrm{mg}$ de amostra para erlenmeyers de $125 \mathrm{~mL}$, adicionaram-se $42 \mathrm{~mL}$ de água deionizada, $100 \mu \mathrm{L}$ de solução $\alpha$-amilase e $1 \mathrm{~mL}$ de solução tampão Acetato de Sódio $2 \mathrm{~mol} . \mathrm{L}^{-1} \mathrm{em}$ $\mathrm{pH} 5,35$. As amostras foram colocadas em banho com agitação à temperatura de $90^{\circ} \mathrm{C}$ por duas horas. A seguir, as amostras foram resfriadas e adicionaram-se $100 \mu \mathrm{L}$ da enzima amiloglucosidase, retornando ao banho por mais duas horas sob agitação a uma temperatura de $55^{\circ} \mathrm{C}$, sendo posteriormente, resfriadas, diluídas e neutralizadas. $\mathrm{O}$ teor de amido foi determinado pelo método de Somogy, adaptado por NELSON (1994), utilizando o fator 0,9 para conversão.

A fração amilose aparente foi determinada pelo método iodo-amido. Foram pesados $150 \mathrm{mg}$ de amostra previamente desengorduradas e adicionaramse $1 \mathrm{~mL}$ ETOH $95 \%$ e $9 \mathrm{~mL} \mathrm{NaOH} 1 \mathrm{molL}^{-1}$, agitando suavemente. Os erlenmeyers foram levados ao banho de água em ebulição por 10 minutos e resfriados à temperatura ambiente. Posteriormente, o material 
foi transferido para balão volumétrico $100 \mathrm{~mL}$ e o volume ajustado, uma alíquota de $18 \mathrm{~mL}$, foi retirado e transferido para tubo de ensaio contendo $2 \mathrm{~mL}$ de $\mathrm{NaOH}$ a 0,09 mol.L $\mathrm{L}^{-1}$. A seguir, alíquota de $5 \mathrm{~mL}$ foi transferida para balão de $100 \mathrm{~mL}$ e adicionaram-se $1 \mathrm{~mL}$ de ácido acético $1 \mathrm{molL}^{-1}$ e $2 \mathrm{~mL}$ de solução de iodo a $0,0157 \mathrm{~N}$ e o volume completado com água deionizada. Os erlenmeyers foram deixados em repouso durante 20 minutos ao abrigo da luz e as absorbâncias foram medidas em espectrofotômetro a $620 \mathrm{~nm}$.

O trabalho foi conduzido no delineamento inteiramente casualizado com três repetições. Os resultados obtidos submeteram-se à análise de variância e a comparação de médias pelo Teste de Tukey em nível de significância de 5\%, utilizando o programa Sisvar.

\section{RESULTADOS E DISCUSSÃO}

$\mathrm{Na}$ análise de cor dos tubérculos, para o parâmetro luminosidade $\left(\mathrm{L}^{*}\right)$ na casca, as cultivares 'Beacon Chipper' e 'BRS Ana' apresentaram maior e menor índice de luminosidade, respectivamente (66,81 e 52,95). Já para a análise das polpas, todas as cultivares apresentaram elevado índice de luminosidade (>76) (Tabela 1). Resultados semelhantes foram obtidos por CAETANO (2006), encontrando valores de luminosidade variando entre 61,7 a 84,7 para diferentes cultivares de batata, indicando cor de polpa mais clara.

Avaliando os parâmetros $\mathrm{a}^{*} \mathrm{e} \mathrm{b}^{*}$ (Tabela 1), verifica-se a presença do componente de cor vermelha (a*) mais intensa na casca para as cultivares 'BRS Ana' e 'Pirassu', podendo esta característica associarse a antocianinas derivadas do grupo pelargonidim (LEWIS et al., 1998). Entretanto, a cultivar 'Beacon Chipper' apresentou presença marcante do componente de cor amarela $\left(b^{*}\right)$, podendo estar relacionada a carotenoides do tipo carotenos e xantofilas EICHHORN \& WINTERHALTER, 2005; JANSEN \& FLAMME, 2006). Atualmente, devido ao seu poder antioxidante, as antocianinas têm sido utilizadas para prevenção do câncer, enquanto, os carotenoides (Provitamina A) são essenciais para o desenvolvimento dos órgãos da visão e formação da pele (SIMONNE et al., 1993).

Os valores de ângulo hue $\left({ }^{\circ} \mathrm{h}\right)$ foram indicativos de que todas as cultivares apresentam polpa e casca de coloração amarela (valores próximos a $90^{\circ} \mathrm{h}$ ). Contudo, as cultivares 'Harley Beckhell' e 'Pirassu' apresentaram cores mais intensas $\left(\mathrm{C}^{*}\right)$ na casca e na polpa, respectivamente, pois, mesmo apresentando valores semelhantes às demais cultivares para ângulo hue, a intensidade de cor foi significativamente maior para essas cultivares (Tabela 1).
Entretanto, o consumidor escolhe batatas através de suas características visuais: cor e brilho, sendo estes fatores importantes para sua aceitação (FERNANDES et al., 2010), pois o consumidor prefere batata com tonalidade clara, atribuindo esta característica à batata recém-colhida (SILVA et al., 2006).

Quando indústrias processadoras buscam cultivares de batatas com qualidades ideais para o processamento, os teores de matéria seca, açúcares totais e amido são os principais parâmetros adotados, contudo, nos dias atuais, o teor de amilose tem levantado grande interesse por estar relacionado à crocância em produtos fritos (TAGGART, 2004).

Dentre as cultivares em estudo, a variação do teor de matéria seca ficou entre 16,2 a $22,2 \%$. As cultivares 'Marcy' e 'Colorado' apresentaram baixos teores de matéria seca, fator limitante para algumas aplicações industriais (Tabela 2). Porém, essas cultivares poderiam ser indicadas a processos que requeiram firmeza e manutenção da forma do tubérculo durante o preparo (FERNANDES et al., 2010).

As cultivares 'BRS Ana', 'Harley Beckhell', 'Snowden' e 'Beacon Chipper' podem ser agrupadas na classe de tubérculos com elevado teor de matéria seca (superior a 20\%); as cultivares 'Pirassu' e 'Marlen', na classe com teores intermediários (entre 18 a 19\%); e as cultivares 'Colorado' e 'Marcy', na classe com baixo teor de matéria seca (inferior a 18\%) (Tabela 2), segundo classificação de CACACE et al. (1994).

O teor de matéria seca adequado para o processamento de batata tipo chips deve ser superior a $20 \%$. Teores superiores a $24 \%$ são indesejáveis, porque produzem fatias quebradiças e causam desgaste excessivo das máquinas fatiadoras. Contudo, a indústria nacional aceita teores em torno de 19,5\% para batata processada tipo chips e teores superiores a $20 \%$ para batata processada tipo palito (PEREIRA et al., 2007).

As cultivares 'BRS Ana', 'Beacon Chipper', 'Snowden' e 'Harley Beckhell' apresentaram teores compatíveis de matéria seca para o processamento na forma de palitos fritos e palitos pré-fritos congelados e as cultivares 'Marlen' e 'Pirassu' apresentaram teores aceitáveis para o processamento na forma chips e/ou palha.

$\mathrm{O}$ teor de açúcares totais dos diferentes tubérculos encontra-se entre 0,09 a $0,23 \%$, respectivamente, para as cultivares 'Snowden' e 'Marlen' (Tabela 2). Segundo FELTRAN et al. (2004), teores elevados de açúcares servem de substrato para a reação de Maillard, resultando em chips de cor escura e gosto amargo. Os teores aceitáveis de açúcares para o processamento na forma de chips encontram-se entre 0,10 e $0,15 \%$ e, 
Tabela 1 - Média \pm desvio padrãoda cor da casca (epiderme) e da polpa das diferentes cultivares de batata.

\begin{tabular}{|c|c|c|c|c|c|}
\hline Cultivar & $\mathrm{L}^{*}$ & $a^{*}$ & $\mathrm{~b}^{*}$ & $\mathrm{C}^{*}$ & ${ }^{\circ} \mathrm{h}$ \\
\hline 'Snowden' & $59,20^{\mathrm{b}}( \pm 0,21)$ & $9,50^{\text {bc }}( \pm 0,16)$ & $29,66^{\mathrm{b}}( \pm 0,20)$ & $8,85^{\mathrm{ab}}( \pm 0,04)$ & $72,23^{\mathrm{bc}}( \pm 0,16)$ \\
\hline 'HarleyBeckhell' & $61,64^{b}( \pm 1,19)$ & $10,71^{\mathrm{b}}( \pm 0,32)$ & $30,22^{\mathrm{b}}( \pm 1,19)$ & $9,05^{\mathrm{a}}( \pm 0,10)$ & $70,45^{\mathrm{c}}( \pm 1,27)$ \\
\hline 'BRS Ana' & $52,95^{\mathrm{c}}( \pm 0,11)$ & $14,15^{\mathrm{a}}( \pm 0,40)$ & $22,60^{\mathrm{c}}( \pm 0,02)$ & $8,57^{\mathrm{bc}}( \pm 0,05)$ & $57,95^{\mathrm{d}}( \pm 0,70)$ \\
\hline 'Pirassu' & $53,50^{\mathrm{c}}( \pm 1,23)$ & $12,88^{\mathrm{a}}( \pm 0,63)$ & $22,48^{\mathrm{c}}( \pm 0,48)$ & $8,41^{\mathrm{c}}( \pm 0,13)$ & $60,21^{\mathrm{d}}( \pm 0,68)$ \\
\hline 'BeaconChipper' & $66,81^{\mathrm{a}}( \pm 0,67)$ & $8,05^{\mathrm{d}}( \pm 0,62)$ & $32,50^{\mathrm{a}}( \pm 0,19)$ & $9,01^{\mathrm{a}}( \pm 0,05)$ & $76,09^{\mathrm{a}}( \pm 1,11)$ \\
\hline 'Marcy' & $59,39^{\mathrm{b}}( \pm 1,76)$ & $8,08^{\mathrm{cd}}( \pm 0,08)$ & $28,45^{\mathrm{b}}( \pm 0,97)$ & $8,55^{\mathrm{c}}( \pm 0,12)$ & $74,14^{\mathrm{ab}}( \pm 0,36)$ \\
\hline $\mathrm{CV}(\%)$ & 2,17 & 4,92 & 2,95 & 1,25 & 1,45 \\
\hline Cultivar & $\mathrm{L}^{*}$ & $a^{*}$ & $\mathrm{~b}^{*}$ & $\mathrm{C}^{*}$ & ${ }^{\circ} \mathrm{h}$ \\
\hline 'Snowden' & $81,28^{\mathrm{b}}( \pm 0,16)$ & $-2,09^{\mathrm{a}}( \pm 0,06)$ & $24,66^{\mathrm{bc}}( \pm 0,60)$ & $6,72^{\mathrm{bc}}( \pm 0,10)$ & $85,14^{\mathrm{b}}( \pm 0,26)$ \\
\hline 'HarleyBeckhell' & $81,66^{\mathrm{b}}( \pm 0,06)$ & $-2,16^{\mathrm{a}}( \pm 0,13)$ & $24,33^{\mathrm{bc}}( \pm 0,54)$ & $6,66^{\mathrm{bc}}( \pm 0,06)$ & $84,93^{\mathrm{b}}( \pm 0,19)$ \\
\hline 'BRS Ana' & $78,47^{\mathrm{c}}( \pm 0,41)$ & $-0,99^{b}( \pm 0,21)$ & $22,09^{\mathrm{d}}( \pm 0,12)$ & $6,50^{\mathrm{c}}( \pm 0,05)$ & $87,43^{\mathrm{a}}( \pm 0,56)$ \\
\hline 'Pirassu' & $76,61^{\mathrm{d}}( \pm 0,21)$ & $-1,28^{\mathrm{b}}( \pm 0,01)$ & $28,34^{\mathrm{a}}( \pm 1,27)$ & $7,36^{\mathrm{a}}( \pm 0,17)$ & $87,41^{\mathrm{a}}( \pm 0,13)$ \\
\hline 'BeaconChipper' & $82,49^{\mathrm{a}}( \pm 0,16)$ & $-2,33^{\mathrm{a}}( \pm 0,06)$ & $25,52^{b}( \pm 0,11)$ & $6,81^{\mathrm{b}}( \pm 0,01)$ & $84,78^{\mathrm{b}}( \pm 0,11)$ \\
\hline 'Marcy' & $81,11^{b}( \pm 0,25)$ & $-2,17^{\mathrm{a}}( \pm 0,03)$ & $23,38^{\mathrm{cd}}( \pm 0,07)$ & $6,51^{\mathrm{c}}( \pm 0,02)$ & $84,70^{\mathrm{b}}( \pm 0,09)$ \\
\hline CV(\%) & 0,36 & 7,22 & 3,07 & 1,60 & 0,40 \\
\hline
\end{tabular}

Letras diferentes na coluna diferem estatisticamente entre si pelo teste de Tukey a $5 \%$ de significância. $\mathrm{L}^{*}$ - luminosidade; a ${ }^{*}$ - variação da coı vermelha $\left(+a^{*}\right)$ ao verde $\left(-a^{*}\right) ; b^{*}$ - variação da cor amarela $\left(+b^{*}\right)$ ao azul $\left(-b^{*}\right) ; C^{*}$ - intensidade da cor e ${ }^{\circ} \mathrm{h}$ - tonalidade da cor.

para o processamento na forma de palitos, entre 0,20 e $0,25 \%$ (ZORZELLA et al., 2003).

Segundo os resultados obtidos, as cultivares 'Harley Beckhell', 'Pirassu' e 'Marcy', apresentam teores de açúcares aceitáveis para processamento na forma de chips e as cultivares 'Marlen' e 'BRS Ana' teores compatíveis para o processamento na forma de palito (Tabela 2). O limite estabelecido na literatura quanto ao teor de açúcares é quase consensual, sendo que, para tubérculos destinados à fritura, encontramse entre 0,2 e 0,3\% (VENDRUSCULO, 1998).

A análise do teor de amido mostrou diferenças entre as cultivares, variando entre 12,67 a $18,70 \%$, que, segundo NOURIAN et al. (2003), fatores como cultivar, época de plantio, temperatura de armazenamento podem influenciar o conteúdo nos tubérculos. Entretanto, KITA (2002) correlacionou a textura com o conteúdo de amido de batatas destinadas à indústria de fritas e observou que teores superiores a $15 \%$ de amido garantiram maior crocância às fatias. Com exceção das cultivares 'Colorado' e 'Marcy', todas as demais apresentam teores de amido compatíveis para o processamento na forma de fritas (Tabela 2). Segundo MORENO (2000), o amido é um dos itens na composição química dos tubérculos que determina a qualidade interna da batata destinada à fritura.

Para fins de processamento de alimentos, são apreciadas batatas com maior teor de amilose, ao contrário da indústria não-alimentar, onde são desejadas batatas com amidos contendo altos níveis de amilopectina (ŠIMKOVA et al., 2013). As cultivares 'BRS Ana' e 'Snowden' apresentaram os maiores teores de amilose nos tubérculos e os menores teores foram observados para as cultivares 'Beacon Chipper' e 'Marcy' (Tabela 2).

Os teores de cinzas variaram ente 0,24 a $0,43 \%$, respectivamente, para as cultivares 'Colorado' e 'BRS Ana' (Tabela 2). A Tabela Brasileira de Composição de Alimentos - TACO (2006) - apresenta valor médio de $0,6 \%$ de cinzas. Segundo FAVORETTO (2005), a variação do teor de cinzas é influenciada pelo manejo adotado, além das condições sazonais. O conteúdo de proteína variou entre 1,40 a $2,45 \%$, respectivamente, para as cultivares 'Colorado' e 'Harley Beckhell'.

A batata in natura pode fornecer cerca de $1,8 \mathrm{~g}$ de proteína por $100 \mathrm{~g}$ de batata, de acordo com a tabela TACO (2006). EVANGELISTA et al. (2011), avaliando diferentes cultivares de batata, encontraram teores de proteína variando entre 1,42 a 2,06\%, para as cultivares 'Ágata' e 'Fontane', que, segundo BÁRTOVÁ \& BÁRTA (2009), a proteína presente na batata apresenta elevado valor nutritivo e biológico.

O teor de fibra alimentar variou entre 0,61 a $0,66 \%$ para as cultivares 'Pirassu' e 'Beacon Chipper', respectivamente (Tabela 2). Essa característica, 
Tabela 2 - Média \pm desvio padrãoda composição centesimal e do teor de amilose das diferentes cultivares de batata.

\begin{tabular}{|c|c|c|c|c|c|c|c|c|}
\hline Cultivar & 'Snowden' & $\begin{array}{l}\text { 'Harley } \\
\text { Beckhell' }\end{array}$ & 'Marlen' & 'Colorado' & 'BRS Ana' & 'Pirassu' & $\begin{array}{l}\text { 'Beacon } \\
\text { Chipper' }\end{array}$ & 'Marcy' \\
\hline Umidade & $79,3^{\text {cd }}$ & $78,6^{\mathrm{cd}}$ & $81,0^{\mathrm{bc}}$ & $83,4^{\mathrm{ab}}$ & $77,8^{\mathrm{d}}$ & $80,4^{\mathrm{cd}}$ & $79,6^{\mathrm{cd}}$ & $83,8^{\mathrm{a}}$ \\
\hline CV\%-1,17 & $( \pm 1,42)$ & $( \pm 0,47)$ & $( \pm 1,12)$ & $( \pm 0,23)$ & $( \pm 0,48)$ & $( \pm 0,69)$ & $( \pm 0,45)$ & $( \pm 0,58)$ \\
\hline Cinzas & $0,37^{\mathrm{b}}$ & $0,39^{\mathrm{b}}$ & $0,30^{\mathrm{c}}$ & $0,24^{\mathrm{d}}$ & $0,43^{\mathrm{a}}$ & $0,40^{\mathrm{b}}$ & $0,28^{\mathrm{d}}$ & $0,27^{\mathrm{d}}$ \\
\hline CV\%-3,43 & $( \pm 0,07)$ & $( \pm 0,02)$ & $( \pm 0,02)$ & $( \pm 0,05)$ & $( \pm 0,02)$ & $( \pm 0,05)$ & $( \pm 0,08)$ & $( \pm 0,02)$ \\
\hline Proteína & $2,00^{\mathrm{ab}}$ & $2,45^{\mathrm{a}}$ & $2,17^{\mathrm{ab}}$ & $1,40^{\mathrm{c}}$ & $2,18^{\mathrm{ab}}$ & $1,95^{\mathrm{b}}$ & $2,26^{\mathrm{ab}}$ & $2,27^{\mathrm{ab}}$ \\
\hline CV\%-8,00 & $( \pm 0,14)$ & $( \pm 0,14)$ & $( \pm 0,04)$ & $( \pm 0,11)$ & $( \pm 0,13)$ & $( \pm 0,27)$ & $( \pm 0,03)$ & $( \pm 0,09)$ \\
\hline Fibra & $0,31^{\mathrm{f}}$ & $0,20^{\mathrm{g}}$ & $0,50^{\mathrm{d}}$ & $0,32^{\mathrm{f}}$ & $0,57^{\mathrm{c}}$ & $0,61^{\mathrm{b}}$ & $0,66^{\mathrm{a}}$ & $0,46^{\mathrm{e}}$ \\
\hline CV\%-2,01 & $( \pm 0,23)$ & $( \pm 0,17)$ & $( \pm 0,10)$ & $( \pm 0,25)$ & $( \pm 0,06)$ & $( \pm 0,15)$ & $( \pm 0,08)$ & $( \pm 0,10)$ \\
\hline Lipídios & $0,04^{\mathrm{e}}$ & $0,08^{\mathrm{b}}$ & $0,11^{\mathrm{a}}$ & $0,06^{\mathrm{cd}}$ & $0,05^{\mathrm{de}}$ & $0,06^{\mathrm{cd}}$ & $0,07^{\mathrm{bc}}$ & $0,05^{\mathrm{de}}$ \\
\hline CV\%-5,55 & $( \pm 0,02)$ & $( \pm 0,02)$ & $( \pm 0,03)$ & $( \pm 0,03)$ & $( \pm 0,02)$ & $( \pm 0,02)$ & $( \pm 0,03)$ & $( \pm 0,02)$ \\
\hline Açúcares & $0,09^{\mathrm{e}}$ & $0,15^{\mathrm{cd}}$ & $0,23^{\mathrm{a}}$ & $0,16^{\mathrm{bc}}$ & $0,21^{\mathrm{ab}}$ & $0,12^{\text {cde }}$ & $0,16^{\mathrm{c}}$ & $0,10^{\text {de }}$ \\
\hline CV\%-8,37 & $( \pm 0,02)$ & $( \pm 0,04)$ & $( \pm 0,06)$ & $( \pm 0,06)$ & $( \pm 0,04)$ & $( \pm 0,02)$ & $( \pm 0,06)$ & $( \pm 0,02)$ \\
\hline Amido & $18,70^{\mathrm{a}}$ & $17,95^{\mathrm{c}}$ & $15,70^{\mathrm{f}}$ & $13,60^{\mathrm{g}}$ & $18,50^{\mathrm{b}}$ & $16,68^{\mathrm{e}}$ & $16,78^{d}$ & $12,67^{\mathrm{g}}$ \\
\hline CV\%-0,06 & $( \pm 0,52)$ & $( \pm 0,37)$ & $( \pm 0,64)$ & $( \pm 0,44)$ & $( \pm 0,38)$ & $( \pm 0,68)$ & $( \pm 0,46)$ & $( \pm 0,22)$ \\
\hline Amilose & $5,50^{\mathrm{ab}}$ & $3,99^{\mathrm{bc}}$ & $3,88^{\mathrm{c}}$ & $4,17^{\mathrm{abc}}$ & $5,69^{\mathrm{a}}$ & $4,41^{\mathrm{abc}}$ & $3,30^{\mathrm{c}}$ & $3,60^{\mathrm{c}}$ \\
\hline CV\%-12,9 & $( \pm 0,48)$ & $( \pm 0,19)$ & $( \pm 0,51)$ & $( \pm 0,45)$ & $( \pm 0,34)$ & $( \pm 0,49)$ & $( \pm 0,15)$ & $( \pm 0,44)$ \\
\hline
\end{tabular}

Letras diferentes na mesma linha diferem estatisticamente entre si pelo teste de Tukey a 5\% de significância.

correlacionada com o bom conteúdo de matéria seca, possibilita a aplicação das cultivares em dietas ricas em fibras ou processamento de alimentos onde tal característica seja requerida.

\section{CONCLUSÃO}

As diferentes cultivares apresentaram características que permitem diversas possibilidades de uso. As cultivares 'Colorado' e 'Marcy' são indicadas para processos que requeiram manutenção dos tubérculos, já as cultivares 'Marlen' e 'Pirassu' são compatíveis para processamento na forma de chips e/ou palha e a cultivar 'BRS Ana' na forma de palito pré-frito e pré-frito congelado.

\section{REFERÊNCIAS}

ANDREU, M.A et al. Genetic markers for processing traits in potato. Crop Breeding and Applied Biotechnology, v.7, n.1. p.67-73, 2007. Disponível em: <http://dx.doi.org/10.12702/19847033.v07n01a10>. Acesso em: 04 jan. 2014.

AOAC (ASSOCIATION OF OFFICIAL ANALYTICAL CHEMISTS INTERNATIONAL). AOAC - International. 18.ed., 2007. Current Through Revision 2.

BÁRTOVÁ, V.; BÁRTA, J. Chemical composition and nutritional value of protein concentrates isolated from potato (Solanum tuberosum L.) fruit juice by precipitation with ethanol or ferric chloride. Journal of Agricultural and Food Chemistry, v.57, n.19, p.9028-9034, 2009. Disponível em:
$<$ http://pubs.acs.org/doi/abs/10.1021/jf900897b $>$. Acesso em: 04 jun. 2014.

CABEZAS-SERRANO, A. et al. Suitability of five different potato cultivars (Solanum tuberosum L.) to be processed as fresh-cut products. Postharvest Biology and Technology, v.53, n.3, p.138-144, 2009. Disponível em: <http://www.sciencedirect.com/science/article/ pii/S0925521409000805>. Acesso em: 03 jan. 2014. doi: 2009.03.009.

CACACE, J.E. et al. Evaluation of potato cooking quality in Argentina. American Potato Journal, v.71, n.3, p.145-153, 1994. Disponível em: <http://link.springer.com/article/10.1007/ BF02849049>. Acesso em: 21 nov. 2013. doi: 10.1007/BF02849049.

CAETANO, D. Inibição do escurecimento na produção de farinha de batata (Solanum tuberosum L.) utilizando secador solar tipo túnel. 2006. 96f. Dissertação (Mestrado em Ciência de Alimentos) Universidade Federal de Lavras.

EICHHORN, S.; WINTERHALTER, P. Anthocyanins from pigmented potato (Solanum tuberosum L.) varieties. Food Research International, v.38, n.8-9, p.943-948, 2005. Disponível em: <http://dx.doi.org/10.1016/j.foodres.2005.03.011>. Acesso em: 05 jun. 2014.

EVANGELISTA, R.M. et al. Qualidade nutricional e esverdeamento pós-colheita de tubérculos de cultivares de batata. Pesquisa Agropecuária Brasileira, v.46, n.8, p.953-960,2011. Disponível em: $\quad<$ http://dx.doi.org/10.1590/S0100-204X2011000800023>. Acesso em: 05 jun. 2014.

FAVORETTO, P. Parâmetros de crescimento e marcha de absorção de nutrientes na produção de minitubérculos de batata cv. 'Atlantic'. Piracicaba, 2005. 98 p. Tese (Mestrado em Agronomia, Fitotecnia) - Escola Superior de Agricultura "Luiz de Queiroz", Universidade de São Paulo. 
FELTRAN, J.C. et al. Technological quality and utilization of potato tubers. Scientia Agricola, v.61, n.6, p.598-603, 2004. Disponível em: <http://www.scielo.br/scielo.php?pid=S010390162004000600006\&script $=$ sci arttext $>$. Acesso em: 20 out. 2013. doi: 10.1590/S0103-90162004000600006.

FERNANDES, A.M. et al. Qualidade físico-química e de fritura de tubérculos de cultivares de batata na safra de inverno. Horticultura Brasileira, v.28, n.3, p.299-304, 2010. Disponível em: <http:// www.scielo.br/pdf/hb/v28n3/v28n3a10.pdf $>$. Acesso em: 08 nov. 2013. doi: 10.1590/S0102-05362010000300010.

FILGUEIRA, F.A.R. Batata inglesa ou andina? Revista Batata Show, v.5, n.13, p.1-2, 2005.

HAASE, N.U. Healthy aspects of potatoes as part of the human diet. Potato Research, v.51, n.3-4,p.239-258, 2008. Disponível em: <http://link.springer.com/article/10.1007/s11540-008-91114>. Acesso em: 02 jan. 2014. doi: 10.1007/s11540-008-9111-4.

IBGE (INSTITUTO BRASILEIRO DE GEOGRAFIA E ESTATÍSTICA). Levantamento Sistemático da Produção Agrícola, nov. 2013. Disponível em: <http://www.ibge.gov.br/ home/estatistica/indicadores/agropecuaria/lspa/lspa 201310.pdf $>$. Acesso em: 04 jan. 2014.

JANSEN, G.;FLAMME, W. Coloured potatoes (Solanum tuberosum L.) - Anthocyanin content and tuber quality. Genetic Resources and Crop Evolution, v.53, n.7,p.1321-1331,2006. Disponível em: <http:// link.springer.com/article/10.1007/s10722-005-3880-2>. Acesso em: 04 jun. 2014. doi:10.1007/s10722-005-3880-2.

KITA, A. The influence of potato chemical composition on crisp texture. Food Chemistry, v.76, n.2, p.173-179, 2002. Disponível em: <http://dx.doi.org/10.1016/S0308-8146(01)00260-6>. Acesso em: 10 jan. 2014

LEONEL, M. et al. Tecnologias de processamento de batata. In:ZAMBOLIM, L. (Org.). Produção integrada de batata. São Carlos: Suprema, 2011. v.2, p.269-289.

LEWIS, C.E. et. al. Determination of antocyanins, flavanoids and phenolic acids in potatoes. I.Colored cultivars of Solanum tuberosum L. Journal Science of Food Agricultural, v.77, n.1, p.45-57, 1998. Disponível em: <http://dx.doi.org/10.1002/ (SICI)1097-0010(199805)77:1<45::AID-JSFA1>3.0.CO;2-S>. Acesso em: 31 jul. 2014.

MORENO, J.D. Calidad de la papa para usos industrials. Disponível em: <http://www.redepapa.org/calidadpapa.pdf $>$. Acesso em: 04 jun. 2014.

NOURIAN, F. et. al. Kinetics of quality change associated with potatoes stored at different temperatures. LebensmittelWissenschaft und-Technologie, v.36, p.49-65, 2003.

PÁDUA, J.G. Aptidão agrícola e industrial de cultivares de batatas introduzidas no Estado de Minas Gerais. Belo Horizonte: EPAMIG, 2007. 76 p.(Relatório técnico).
PEREIRA, A. da S. et al. Genótipos de batata com baixo teor de açúcares redutores. Horticultura Brasileira, Brasília, v.25, n.2, p.220-223, 2007. Disponível em: <http://www.scielo.br/pdf/hb/ v25n2/17.pdf>. Acesso em: 10 out. 2013. doi: 10.1590/S010205362007000200018

PINTO, C.A.B.P. Desenvolvimento de novas cultivares de batata. Batata Show - A revista da Batata. Ano 01, n.2, 38p, 2001. Disponível em: <http:/www.abbabatatabrasileira.com.br/images/ pdf/rbs_2.pdf $>$. Acesso em: 20 nov. 2013.

ROMMENS, C.M. et al. Tastier and healthier alternatives to French Fries. Journal of Food Science, v.75, n.4, p.H109-H115,2010. Disponível em: <http://dx.doi.org/10.1111 /j.1750-3841.2010.01588.x>. Acesso em: 20 dez. 2013.

SANNY, M. et al. Is lowering reducing sugars concentration in French fries an effective measure to reduce acrylamide concentration in food service establishments? Food Chemistry, v.135, n.3, p.2012-2020, 2012. Disponível em: <http://dx.doi. org/10.1016/j.foodchem.2012.06.052>. Acesso em: 20 dez. 2013.

SILVA, G.O. et al. Características físico-químicas de amidos modificados de grau alimentício comercializados no Brasil. Ciência e Tecnologia de Alimentos, v.26, n.1, p.188-197, 2006. Disponível em: <http://www.scielo.br/pdf/cta/v26n1/28869.pdf>. Acesso em: 04 jun. 2014. doi: 10.1590/S0101-20612006000100030.

SILVEIRA, J. et al. Quem é o consumidor brasileiro de frutas e hortaliças? Hortifruti Brasil, p.8-23, 2011. Disponível em: $<$ http://www.cepea.esalq.usp.br/hfbrasil/edicoes/103/mat capa. pdf>. Acesso em: 27 dez. 2013.

ŠIMKOVÁ D. et al. Effect of cultivar, location and year on total starch, amylose, phosphoruscontent and starch grain size of high starch potato cultivars for food andindustrial processing. Food Chemistry, v.141, n.4, p.3872-3880, 2013. Disponível em: $<$ http://dx.doi.org/10.1016/j.foodchem.2013.06.080>. Acesso em: 17 jan. 2014

SIMONNE, A.H. et al. Assessment of betacarotene content in sweet potato breeding lines in relation to dietary requirements. Journal of Food Comp Anal, v.6, p.336-345. 1993.

TACO. Tabela Brasileira de Composição de Alimentos. 2.ed. Campinas: Universidade Estadual de Campinas, 2006. Disponível em: <http://www.unicamp.br/nepa/taco/contar/taco_4_edicao_ ampliada e revisada.pdf?arquivo $=$ taco 4 versao ampliada e revisada.pdf $>$. Acesso em: 05 jun. 2014.

TAGGART, P. Starch as an ingredient: manufacture and applications. In: ELIASSON, A. (Ed.). Starch in food: structure, function and applications. Woodhead, 2004. p.363-392.

ZORZELLA, C.A. et al. Caracterização física, química e sensorial de genótipos de batata processados naforma chips. Brazilian Journal of Food Technology, v.6, p.15-24, 2003. Disponível em: $<$ http://bjft.ital.sp.gov.br/artigos/html/busca/PDF/v6nu108a.pdf $>$. Acesso em: 03 jan. 2014. 